\title{
Effects of KT-362, a New Calcium Release Blocker, on Vascular Selectivity and Hemodynamic Actions in Anesthetized Dogs
}

\author{
Shuichi WAKABAYASHI, Seiichiro MOCHIZUKI, Akira TOMIYAMA \\ and Shoji SHIBATA ${ }^{1}$ \\ Research Laboratory, Kotobuki Seiyaku Co., Ltd., Hanishina, Nagano 389-06, Japan \\ 'Department of Pharmacology. School of Medicine, University of Hawaii. \\ Honolulu, Hawaii 96822, U.S.A. \\ Accepted June 1, 1990
}

\begin{abstract}
Pharmacological properties of 5-(3-((2-(3,4-dimethoxyphenyl)ethyl)amino)-1-oxopropyl)-2,3,4,5-tetrahydro-1,5-benzothiazepine fumarate (KT-362), a newly synthesized calcium release blocker, were studied by comparing its vascular selectivity and cardiovascular actions with those of verapamil, a calcium entry blocker. The relaxing effect of KT-362 in rabbit femoral and basilar artery strips contracted with norepinephrine was greater than that in aortic and coronary artery strips. In anesthetized mongrel dogs, KT-362 $(0.1-3.0 \mathrm{mg} / \mathrm{kg}, \mathrm{i} . \mathrm{v})$ ) decreased the mean blood pressure, heart rate and total peripheral resistance in a dose-dependent manner, while cardiac output increased slightly despite a decrease in left ventricular pressure. This is consistent with the data on verapamil. Both i.a. and i.v. injections of KT-362 produced a marked dose-dependent increase in vertebral and femoral blood flow. Pretreatment of atropine, propranolol or diphenhydramine exerted no significant effect on the KT-362-induced vasodilation. Verapamil caused a marked increase in the vertebral and coronary blood flows after the injections, but only a slight increase in femoral blood flow. KT-362 at the dose of $10 \mathrm{mg} / \mathrm{kg}$. i.v., had no significant effect on the $\mathrm{PQ}$ interval on the electrocardiogram in anesthetized dogs, but $0.1 \mathrm{mg} / \mathrm{kg}$ of verapamil increased this interval significantly. These results suggest that KT-362 has properties similar to calcium entry blockers such as verapamil on systemic hemodynamic actions except for the reactivity of vasculatures.
\end{abstract}

KT-362 (Fig. 1) is a recently developed calcium release blocker. Although this compound is structurally related to the classic calcium entry blockers, diltiazem and verapamil, it acts by inhibiting intracellular calcium release from norepinephrine (NE) - and caffeine-sensitive stores on the vascular smooth muscle rather than blocking calcium influx through voltage sensitive channels (1). Eskinder and co-workers suggested that the mechanism of this inhibition by KT-362 is the

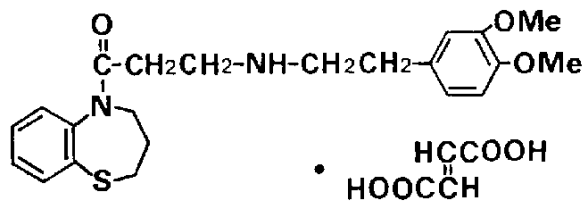

Fig. 1. Chemical structure of KT-362. result of blocking phosphatidyl inositol hydrolysis (2).

In atrial muscle, Kondo et al. have shown that KT-362 inhibited the first beat contraction after a rest period, which was resistant to nifedipine or tetrodotoxin, but largely inhibited by ryanodine or caffeine (3). Furthermore, they have shown that KT-362 inhibited the plateau phase of the action potential as well as contraction in ventricular muscle isolated from hibernating chipmunks which is resistant to calcium entry blockers (3). From a series of pharmacological studies, it is assumed that the primary inhibitory action of KT-362 on vascular smooth muscle and ventricular muscle is due to an interference with the release of calcium from the intracellular store. Little information is available on 
the hemodynamic action of calcium release blockers in vivo. The present studies were performed to obtain further insight into the vascular selectivity and cardiovascular action of KT-362 by comparison with the data on the calcium entry blocker verapamil.

\section{Materials and Methods}

Relaxing effects on various arteries contracted with NE: Male New Zealand white rabbits weighing $1.5-2 \mathrm{~kg}$ were killed by a blow to the head. The chest and skull were opened to remove the thoracic aorta and the coronary. basilar and femoral arteries. After excess fat and connective tissues were removed, the various arteries were cut into helical strips. They were mounted vertically in organ baths containing $20 \mathrm{ml}$ of Krebs solution of the following composition: $120.3 \mathrm{mM} \mathrm{NaCl} .4 .8 \mathrm{mM}$ $\mathrm{KCl}, 1.2 \mathrm{mM} \mathrm{CaCl}_{2}, 1.3 \mathrm{mM} \mathrm{MgSO}_{4} 7 \mathrm{H}_{2} \mathrm{O}$. $1.2 \mathrm{mM} \mathrm{KH}_{2} \mathrm{PO}_{4}$, and $24.2 \mathrm{mM} \mathrm{NaHCO}_{3}$ and $5.5 \mathrm{mM}$ glucose at $\mathrm{pH} 7.4$. The tissue bath solution was maintained at $37^{\circ} \mathrm{C}$ and bubbled with a $95 \% \quad \mathrm{O}_{2}$ and $5 \% \quad \mathrm{CO}_{2}$ gas mixture. Ligatures were placed around both ends of the muscle strips, one attaching the muscle to a glass holder and the other, to a transducer adjusted to give initial stretched tensions of $1.5 \mathrm{~g}$ for the aorta, $0.2 \mathrm{~g}$ for the basilar. $1.0 \mathrm{~g}$ for the femoral and $0.4 \mathrm{~g}$ for the coronary arteries. Isometric tension changes were recorded through a force-displacement transducer (Grass, FT-3) connected to a six channel Grass polygraph. Various arteries were contracted with NE $\left(10^{-5} \mathrm{M}\right)$, after which increasing concentrations of KT-362 were administered.

Cardiovascular actions in anesthetized dog: To evaluate the cardiovascular effects of the compounds, several types of experiments were performed, as will be described below. In all experiments, mongrel dogs of either sex weighing from 8 to $20 \mathrm{~kg}$ were anesthetized with sodium pentobarbital $(30 \mathrm{mg} / \mathrm{kg}$, i.v.). After the trachea was intubated, the animal was artificially ventilated with room air in a tidal volume of $20 \mathrm{ml} / \mathrm{kg}$ at a rate of 20 breaths/min using a positive-pressure respirator (Shinano, SN-480-3). The body temperature was maintained at $37-38^{\circ} \mathrm{C}$ with a heating pad.

Blood pressure (BP) was measured from the right femoral artery by means of a pressure transducer (Nihon Kohden, TP-200T). Heart rate $(H R)$ was obtained from a heart rate counter (Nihon Kohden, AT-601G) triggered by the arterial blood pressure wave. All recordings were made on a heat-writing recticorder (Nihon Kohden. WT-685G). Left ventricular pressure (LVP) was measured from the left ventricular chamber through the left common carotid artery by means of a pressure transducer (Nihon Kohden. TP. 200T).

Maximum velocity of LVP (dLVP/dt max) was obtained by differentiation of the upstroke spike of the LVP pulse with a physiodifferentiator (Nihon Kohden, ED-601G). After a left thoracotomy was performed at the 5 th left intercostal space, a precalibrated noncannulating flow probe was placed around the ascending aorta to measure the cardiac output (CO) with an electromagnetic flowmeter (Nihon Kohden, MFV-2100). Total peripheral resistance (TPR) was calculated with an analog multiplier (Nihon Kohden, EO-601G) dividing the mean BP by the aortic flow. Arterial blood taken from the right carotid artery was led to the left vertebral artery, the left femoral artery and the left anterior descending coronary artery by a short extracorporeal loop. An electromagnetic flow probe of the extracorporeal type was inserted in this circuit. All blood inflow was measured using an electromagnetic flow meter with a probe of the extracorporeal type. The drugs, in a volume of $0.03 \mathrm{ml}$, were given by a microinjection into a rubber tube connected close to the arterial cannula for a period of $5 \mathrm{sec}$. Extracorporeal perfusion of selected arterial beds was done under conditions of controlled pressure, and the mean perfusion pressure was taken as the mean systemic blood pressure. Even though the drugs were given i.a. at low doses, neither systemic nor perfusion mean blood pressure (MBP) changed. Heparin sodium $(400 \mathrm{U} / \mathrm{kg}$. i.v.) was administered to prevent clotting. Other than injection into the artery, all drugs were given into the right femoral vein. Mean blood flow (BF) was measured with a noncannulating electromagnetic flow probe at the left vertebral artery, circumflex branch of the left coronary and the left femoral artery. A flow probe of adequate size was placed 
around each artery. The vehicle for each drug was saline. Control injection of the vehicle. each in a volume equivalent to that used for drug administration, produced no significant changes in cardiovascular parameters. KT362 was synthesized at Organic Chemistry Research Department, Kotobuki Seiyaku Co., Ltd. Verapamil hydrochloride and KT-362 were freshly dissolved in physiological saline at the required concentration.

Statistical analysis: The data in the figures and tables are expressed as the meantS.E. Statistical significance of differences was evaluated by Student's $t$-test. Differences were considered significant if $P$ value was $<0.05$.

\section{Results}

Relaxing effects of KT-362 on various arteries contracted with NE: Figure 2 shows the relaxing effect of $K T-362\left(10^{-7}-10^{-4} \mathrm{M}\right)$ on aortic, femoral basilar and coronary arteries previously contracted with $10^{-5} \mathrm{M}$ of NE. Femoral and basilar strips contracted with NE began to relax at a threshold concentration of $3 \times 10^{-7} \mathrm{M} \mathrm{KT}-362$ and the preparation had relaxed almost completely at $10^{-5} \mathrm{M}$. On the other hand, in aortic and coronary strips.
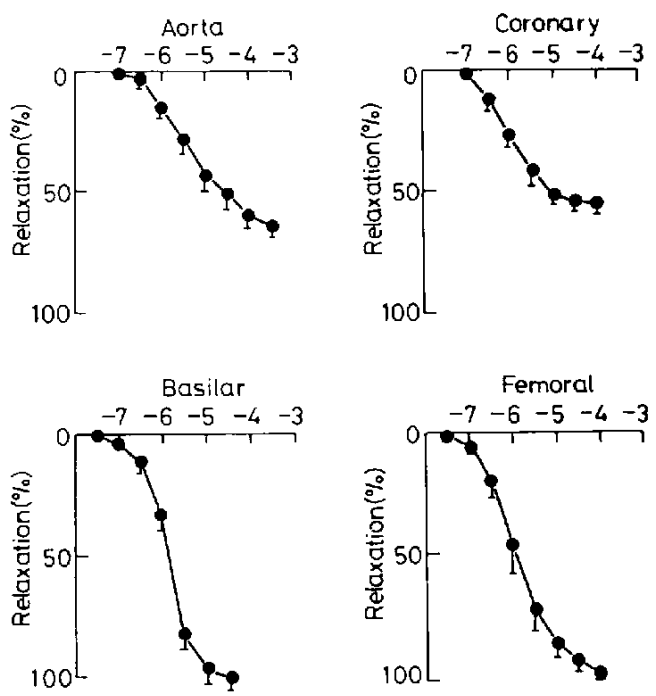

Fig. 2. The relaxing effect of KT-362 on various arteries contracted with norepinephrine $\left(10^{-5} \mathrm{M}\right)$. The relaxing percent (\%) is expressed as $100 \%$ of papaverine $\left(10^{-4} \mathrm{M}\right)$-induced relaxation. Values represent the mean \pm S.E. of five preparations. the maximum relaxing effect of KT-362 was only about 60 percent. Therefore, the relaxing effect of KT-362 in femoral and basilar arterial strips contracted with NE was greater than that in aortic and coronary arterial strips.

Hemodynamic effects of KT-362 and verapamil in the anesthetized dogs: The effects of $K T-362$ in a dose range of 0.1 to 3.0 $m g / k g$, i.v., on BP, MBP. HR, LVP, dLVP $/ \mathrm{dt}$ max., $C O$ and TPR were examined in comparison with those of verapamil $(0.01$ to 0.3 $\mathrm{mg} / \mathrm{kg}$, i.v.). KT-362 produced dose-related effects on cardiovascular parameters, as shown in Fig. 3. In general, the response to KT-362 was rapid at onset, and maximum changes in cardiovascular variables occurred from 0.5 to $1.0 \mathrm{~min}$ after an intravenous bolus injection of KT-362. Table 1 summarizes the effects of KT-362 and verapamil on cardiovascular parameters in anesthetized dogs. KT$362(0.3-3.0 \mathrm{mg} / \mathrm{kg}$, i.v.) produced a doserelated decrease in MBP $(-6.0 \pm 2.7$ to $-39.2 \pm 3.8 \%)$. TPR $(-7.9 \pm 4.0$ to $-47.7 \pm$ $6.0 \%)$. LVP $(-3.9 \pm 2.3$ to $-28.5 \pm 3.7 \%)$ and $\mathrm{dLVP} / \mathrm{dt} \max (-0.7 \pm 0.4$ to $-24.5 \pm 4.8 \%)$. HR was also decreased slightly by a bolus injection of KT-362. However, $\mathrm{CO}$ increased despite a decrease in LVP and dLVP/dt max. Intravenous administration of KT-362. which caused a $30 \%$ decrease in the MBP, produced $-3.3 \%,-21.5 \%, \quad-15.5 \%, \quad+18.0 \%$ and $-36.5 \%$ change in the HR, LVP. dLVP/dt max. $\mathrm{CO}$ and TPR, respectively. Similar results were also obtained with verapamil in doses of 0.01 to $0.3 \mathrm{mg} / \mathrm{kg}$. i.v. (Table 1).

Effect of KT-362 given i.a. into the vertebral, coronary and femoral vascular beds in the anesthetized dog: Figure 4 summarizes the effect of KT-362 on various BFs given into the vertebral, coronary and femoral arteries. The initial baseline of vertebral BF, coronary BF and femoral BF were $10.3 \pm 1.4 \mathrm{ml} / \mathrm{min}(n=4)$, $17.1 \pm 1.6 \mathrm{ml} / \mathrm{min}(\mathrm{n}=4)$ and $29.4 \pm 3.1 \mathrm{ml} /$ $\min (n=4)$, respectively. Intra-arterial injection of $100 \mathrm{~kg}$ of KT-362, which caused about a $120 \%$ increase in the vertebral BF. produced about $28 \%$ and $47 \%$ increase in the coronary and femoral BF, respectively. The order of the potencies of KT-362 on each arterial BF increase was: vertebral $>$ femoral $>$ coronary BF, at any dose used $(10-1000 / \mathrm{g}$, i.a.) 


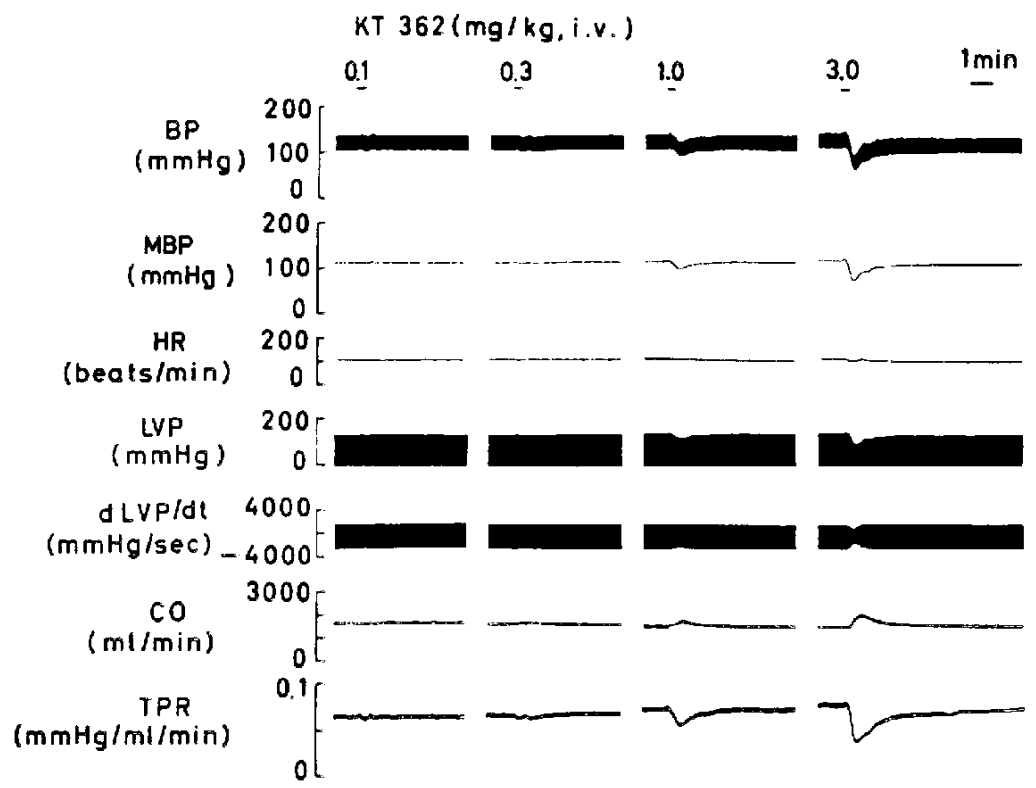

Fig. 3. Cardiovascular effects of KT-362 in the anesthetized open-chest dog. The recording shown is a typical one from five experiments. BP: blood pressure, MBP: mean blood pressure, HR: heart rate, LVP: left ventricular pressure, dLVP/dt max: differentlated upstroke spike of left ventricular pressure, CO: cardiac output. TPR: total peripheral resistance.

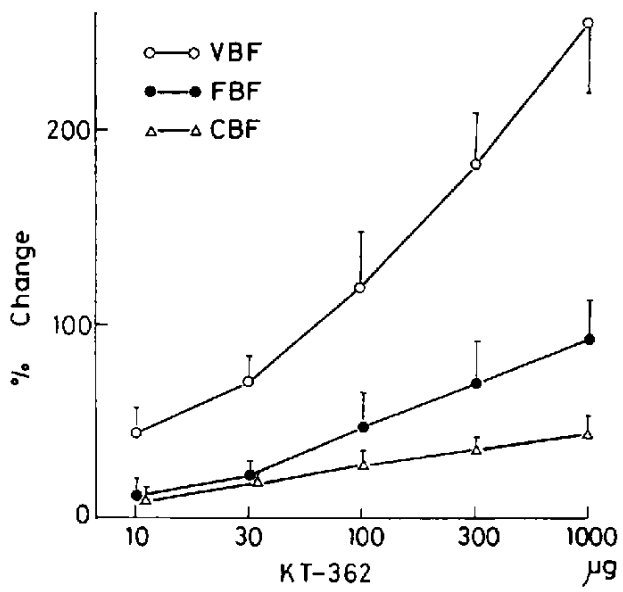

Fig. 4. Changes in vertebral BF (VBF), femoral BF (FBF) and coronary BF (CBF) elicited by i.a. injection of KT-362. Differences in BF are expressed as percentage of changes from the control. Values represent the mean \pm S.E. of six experiments.

Pretreatment with atropine, propranolol and diphenhydramine caused a complete blockade of the arterial response to acetylcholine, isoproterenol and histamine, respec- tively. In contrast, a bolus injection of either blocker exerted no significant effect on the $\mathrm{KT}-362$-induced vasodilation (Fig. 5).

Effects of KT-362 given i.v. on the vertebral, coronary, and femoral $\mathrm{BF}$ in the anesthetized dog: The effects of $\mathrm{KT}-362(0.1$ to $3 \mathrm{mg} / \mathrm{kg}$. i.v.) on vertebral, coronary and femoral BF were examined in comparison with those of verapamil (0.01 to $0.3 \mathrm{mg} / \mathrm{kg}$, i.v.). Both compounds increased the BF in a dose-dependent manner. However, their effects on these vascular beds were different, as shown in Fig. 6. The increase percent of vertebral and femoral BF elicited by KT-362 (0.1 to $1 \mathrm{mg} /$ $\mathrm{kg}$, i.v.) was higher than that of coronary BF. but was the same at a high dose of KT-362 ( $3 \mathrm{mg} / \mathrm{kg}$ ). On the other hand, verapamil at any dose used (0.01 to $0.3 \mathrm{mg} / \mathrm{kg}$. i.v.) augmented vertebral and coronary BF more intensely with little effect on femoral BF, in dicating a selective effect on vertebral and coronary vasculature as opposed to femoral vessels. Both compounds caused a systemic hypotension which was accompanied by an increase in BF.

Electrocardiographic (ECG) effects of KT- 


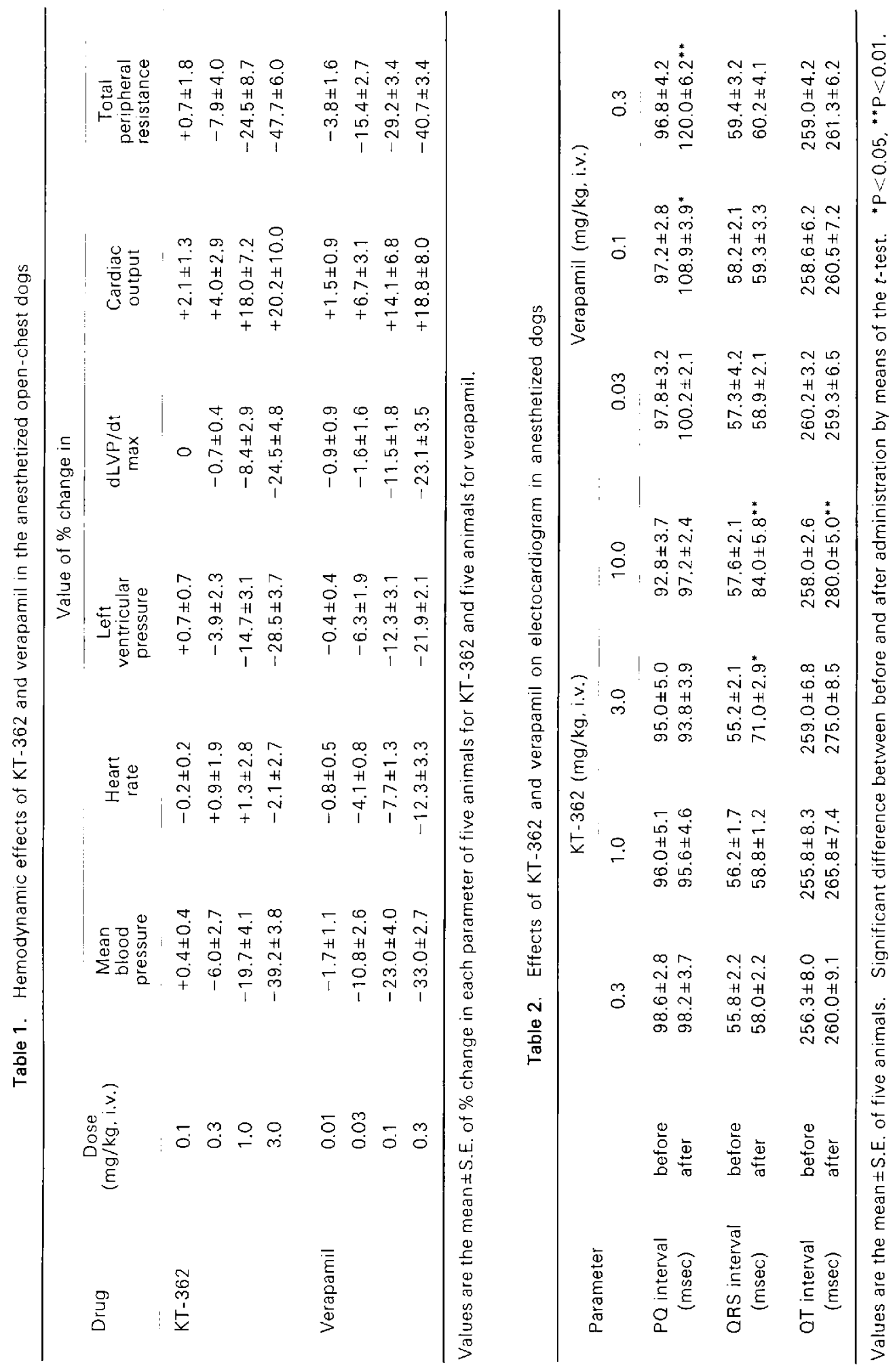



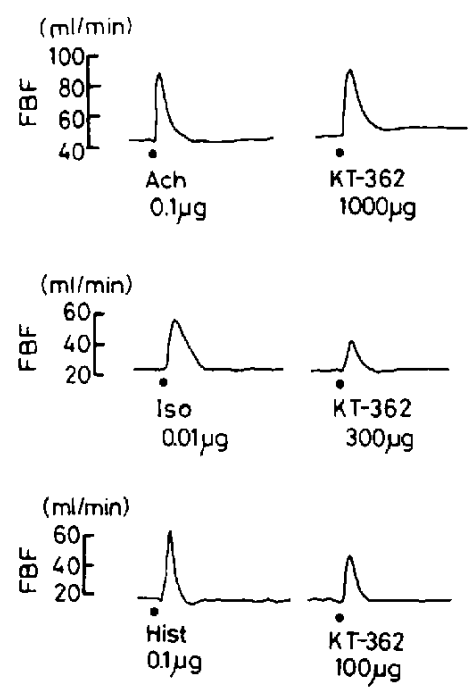

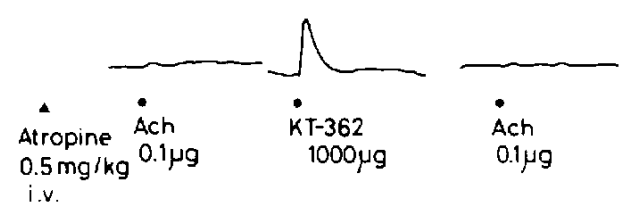

i.v.
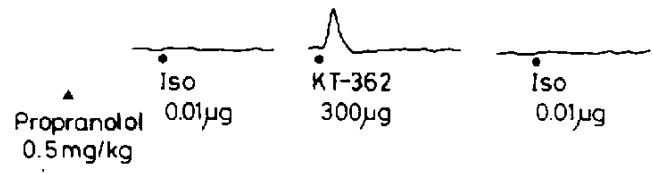

i. $v$.
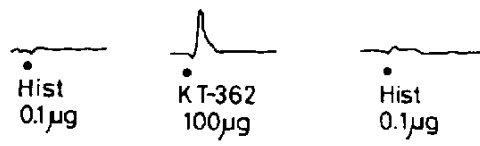

\section{Diphenhydramine \\ $3 \mathrm{mg} / \mathrm{kg}$}

i.v.

Fig. 5. Effect of bolus injections (femoral vein) of atropine $(0.5 \mathrm{mg} / \mathrm{kg})$, propranolol $(0.5 \mathrm{mg} / \mathrm{kg})$ or diphenhydramine $(3 \mathrm{mg} / \mathrm{kg}$ ) on KT-362-induced increase of femoral BF (FBF). Acetylcholine (Ach: $0.1 \mu \mathrm{g})$, isoproterenol (Iso: $0.01 \mu \mathrm{g})$. histamine (Hist: $0.1 \mu \mathrm{g})$, and KT-362 (100-1000 $\mu \mathrm{g}$ ) were injected into the femoral artery.
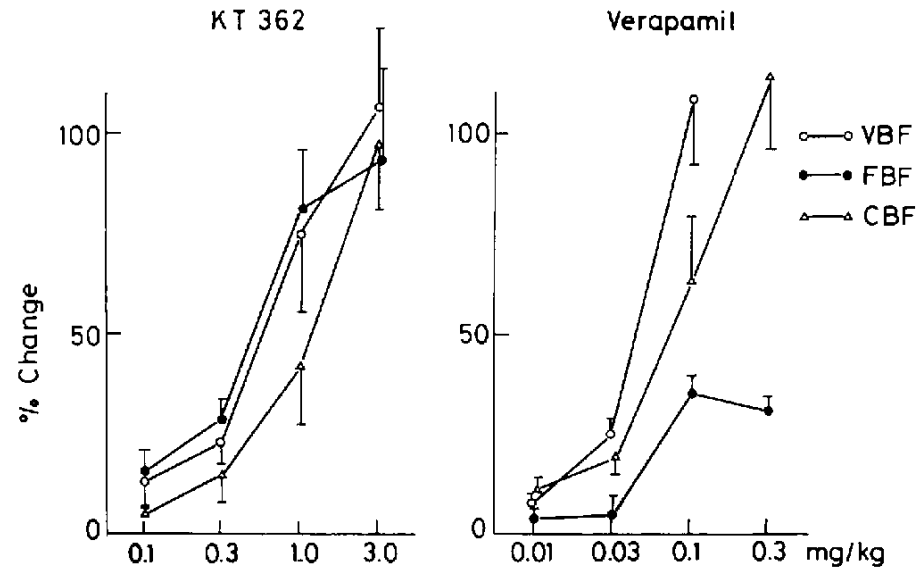

Fig. 6. Changes in vertebral $B F(V B F)$, femoral $B F(F B F)$ and coronary $B F(C B F)$ elicited by i.v. injection of KT-362 and verapamil. Changes in BF are expressed as percentage of change from the control Values represent the mean $\pm S$.E. of six experiments.

362 and verapamil: The effects of KT-362 and verapamil administered by a bolus i.v. injection on ECG parameters are summarized in Table 2. After $10 \mathrm{mg} / \mathrm{kg}$, i.v. of $\mathrm{KT}-362$, there was no change in the PQ interval, but the QT and QRS interval was increased from $258.0 \pm$ 2.6 to $280.0 \pm 5.0$ and from $57.6 \pm 2.1$ to $84.0 \pm$
5.8 milliseconds, respectively. On the other hand. $0.1 \mathrm{mg} / \mathrm{kg}$ of a bolus i.v. injection of verapamil increased the $\mathrm{PO}$ interval from $97.2 \pm 2.8$ to $108.9 \pm 3.9$ milliseconds $(P<$ 0.05 ) without any effect on the QRS and QT interval. 


\section{Discussion}

The relaxing effect of KT-362 in femoral and basilar arterial strips contracted with NE was greater than that in aortic and coronary arterial strips. Several investigators have shown that contractions of vascular smooth muscles by stimulation of alpha-1. but not alpha-2, adrenoceptors are resistant to calcium entry blocking agents, suggesting that alpha-1 adrenoceptor-mediated contractions are mainly initiated by a release of cellular bound calcium and maintained by calcium entry through calcium entry blocker-insensitive pathways (4-6). It has been reported that NE-induced calcium-dependent, D-600insensitive contractions in rabbit aorta were not affected by $\mathrm{KT}-362$ at $10^{-6} \mathrm{M}$ or $10^{-5} \mathrm{M}$ and only slightly depressed by $10^{-4} \mathrm{M}$. suggesting that the inhibitory action of KT-362 may not be primarily related to calcium entry through specific receptor-activated pathways (1). Therefore, the relaxing effect of KT-362 in arterial strips contracted with NE may primarily be mediated by inhibition of intracellular calcium release. These results indicate that the contraction of basilar and femoral arterial strips contracted with NE may be mediated by the release of cellular bound calcium more than in the case of coronary and aortic strips.

With regard to $K T-362$, in vivo data are in general agreement with verapamil and prior studies demonstrating that calcium entry blockers, including diltiazem, nimodipine and nicardipine, lower arterial BP and produce increases in various BFs (7-10). KT-362 decreased the left ventricular pressure and $\mathrm{dLVP} / \mathrm{dt}$ max remarkably in a dose-dependent manner, which is consistent with the data of verapamil. Normally, there is a close correlation between $V$ max of the slow action potential induced by isoproterenol under the high dose of $\mathrm{KCl}$ and the force of contraction (11). However, KT-362 is less potent than verapamil in the blockade of slow action potential. Verapamil abolished the slow action potential at $5 \times 10^{-6} \mathrm{M}(12)$, while $\mathrm{KT}$ 362 only slightly depressed this at $10^{-4} \mathrm{M}$ (13). Therefore, the mechanism of the negative inotropic action of KT-362 is different from that of verapamil. KT-362 has a $\mathrm{Na}^{*}$ channel blocking effect (13) which is attributed to a decrease in intracellular sodium. resulting in a decreased sodium-calcium exchange that leads to a lowering of intracellular calcium $(14,15)$. Further, Kondo et al. (3) have shown that KT-362 inhibited the plateau phase of the action potential as well as contractions in ventricular muscle isolated from hibernating chipmunks that are resistant to calcium entry blockers. It has been reported that inositol triphosphate $\left(I_{3}\right)$ can release calcium from isolated cardiac muscle sarcoplasmic reticulum $(16,17)$, and $I P_{3}$ is decreased by KT-362 as a result of a blockade of phosphatidyl inositol hydrolysis (2). Therefore, the mechanism of the negative inotropic effect of KT-362 is fundamentally related to an inhibition of intracellular calcium release and a $\mathrm{Na}^{+}$channel blocking action, with additional contribution from the effects on calcium entry.

KT -362 and verapamil increased $\mathrm{CO}$ by $18.0 \%$ and $10.0 \%$, respectively, at a dose that lowered MBP by $30 \%$, despite a decrease in the left ventricular pressure and dLVP/dt max. It is considered that the increase in $\mathrm{CO}$ is ascribable to the afterload reduction, leading to an increase of venous return. The increase of $\mathrm{CO}$ by i.v. administration of KT-362 was greater than that of verapamil, suggesting that $\mathrm{KT}-362$ is more preferential to peripheral vessels than verapamil.

In anesthetized dogs verapamil increased the $\mathrm{PQ}$ interval in a dose-dependent manner. but a high dose of KT-362 (10 mg/ $\mathrm{kg}$, i.v.) did not have any effect on this interval. In the cases of vasodilator drugs having a calcium entry blocking action such as verapamil in the treatment of hypertension and angina, impairment of atrioventricular conduction leading to an A- $V$ blocking action is an undesirable effect. Therefore, KT-362 is expected to be devoid of such undesirable effects because it decreases cytosolic calcium concentration by a different mechanism from that of calcium entry blockers.

Both i.a. and i.v. injections of KT-362 produced a dose-dependent increase in various arterial blood flaws. The vasodilator effects of an i.a. injection of KT-362 in anesthetized dogs were not altered by atropine, propranolol or diphenhydramine treatment. 
The action of KT-362 is clearly different from other pharmacological vasodilating agents such as acetylcholine, isoproterenol or histamine. It has often been reported in experiments with anesthetized dogs that some differences were found in the reactivity of vasculatures to the vasodilator drugs. KT $362(0.1$ to $1 \mathrm{mg} / \mathrm{kg}$, i.v.) increased vertebral and femoral BF more intensely than coronary $B F$, but verapamil exerted a preferential effect on vertebral and coronary $\mathrm{BF}$ in contrast to the femoral BF supplied to the hindquarter. The same result is shown in the case of i.a. injection of KT-362. One of the reasons why i.a. injection of KT-362 increased vertebral BF remarkably seems to be associated with the difference in the initial baseline of blood flow. The initial baseline of vertebral BF is about one third times lower as compared with that of femoral BF, indicating that the plasma concentration of KT-362 administered into the vertebral $B F$ is three times higher than the femoral blood flow. Farber and Gross reported that KT-362 had minimal coronary vasodilator activity as compared with diltiazem in anesthetized dogs (18). Takenaka et al. (19) and Sato et al. (20) reported that calcium entry blockers such as nicardipine. diltiazem and nifedipine increased vertebral and coronary BF more intensely than femoral $B F$, indicating that calcium entry blockers appear to exert a preferential effect on the cerebral and coronary vasculatures as opposed to the vessels supplied to the hindquarter. These results of previous reports are consistent with our data. There is minimal calcium release from internal stores in canine coronary vascular smooth muscle during contraction (21). This may be the reason why KT-362 had minimal coronary vasodilating activity in the present experiments. The reason why $3 \mathrm{mg} /$ $\mathrm{kg}$ of KT-362 markedly increased coronary BF seems to be ascribed to a calcium entry blocking action which KT-362 has at a high dose. The present study revealed that the cardiovascular action of the calcium release blocker KT-362 is in general agreement with calcium entry blockers. This is based on the fact that both agents decrease free cytosolic calcium. On the other hand, differences were observed in the vascular reactivity and the $P O$ interval of ECG. which is ascribed to the dif- ferent mechanism of decreasing cytosolic calcium concentration

Since the release of intracellular calcium is greater than the entry through slow calcium channels in ventricular muscles and intracelluar calcium accumulation plays a primary role in the pathophysiology of myocardial ischemia $(22,23)$, KT-362 may have some advantage over calcium entry blockers with regard to limiting cytosolic calcium concentration. In fact, we have reported that KT-362 prevented ouabain-, epinephrine- and chloroform-induced arrhythmias because of its $\mathrm{Na}^{+}$ channel blocking action and inhibition of intracellular calcium release (24). Furthermore. KT-362 has been shown to reduce the extent of myocardial injury resulting from $90 \mathrm{~min}$ of coronary artery occlusion and $3 \mathrm{hr}$ of reperfusion owing to a decrease in myocardial energy requirements during occlusion as a result of inhibition of intracellular calcium release (25). Recently it has also been reported that other drugs that suppress the calcium mobilization from intracellular store sites should be effective on ventricular arrhythmia (26-28) and cerebral vasospasm (29). Therefore, this type of compound with new mechanisms of action on calcium movement in vascular smooth muscle and ventricular muscle may introduce a novel therapeutic approach for cardiac vascular diseases.

Acknowledgment: We wish to express our sincere appreciation to Prof. H. Saito (Department of Chemistry Pharmacology, Faculty of Pharmaceutical Science, University of Tokyo) for his valuable discussions about our data.

\section{References}

1 Shibata, S., Wakabayashi, S., Satake, N., Hester, R.K., Ueda, S. and Tomiyama, A.: Mode of vasorelaxing action of $5-(3-((2)-(3.4-$ dimethoxyphenyl)ethyl) amino-1-oxopropyl) -2,3,4,5-tetrahydro-1.5-benzothiazepine fumarate (KT-362), a new intracellular calcium antagonist. J. Pharmacol. Exp. Ther. 244, 16-22 (1987)

2 Eskinder, H., Hillard, C.J. and Gross, G.J.: Effect of KT-362, a new intracellular calcium antagonist, on norepinephrine-induced contraction and inositol monophosphate accumulation in canine femoral artery. J. Cardiovasc. Pharmacol. 13, 502-507 (1989)

3 Kondo, N., Kodama, I., Shibata, S. and Satake, N.: Effects of KT-362, a new anti-arhythmic agent 
with vasodilating action, on the intracellular calcium kinetics in rabbit cardiac muscles. Fed. Proc. 3, 591 (1989)

4 Van Meel, J.C.C., Dejonge, A., Wilffert, B., Kalkman, H.O., Timmermans, P.B.M.W.M. and Van Zweiten, P.A.: Vascular smooth muscle contraction initiated by postsynaptic alpha2-adrenoceptor activation is induced by an influx of extracellular calcium. Eur. J. Pharmacol.69, 205208 (1981)

5 Godfraind, T., Miller, R.C. and Socrates Lima, A.: Selective of alpha 1 - and alpha 2-aorta. Br. J. Pharmacol. 77, 597-604 (1982)

6 Demarinis, R.M., Lavanchy, P., Hieble, J.P., Jom, K.F. and Matthews, W.D.: N-(2-Hydroxy$\mathrm{t}$-(2-(methylamino)ethyl)phenyl) methanesulfon amide. A potent agonist which release intracellular calcium by activation of alpha 1-adrenoceptors. J. Med. Chem. 28, 245-247 (1985)

7 Takenaka, T., Usuda, S., Nomura, T., Maeno, H. and Sado, T.: Vasodilator profile of a new 1,4dihydropyridine derivative, 2.6-dimethyl-4-(3nitrophenyl) - 1,4-dihydropyridine - 3,5-dicarboxylic acid 3-(2-(N-benzyl-N-methylamino)) ethyl ester 5-methyl ester hydrochloride (YC-93). Arzneimittelforschung 26, 2172-2176 (1976)

8 Flaim, S.F., Annibali, J., Newan, E.D. and Zeils, R.: Effects of diltiazem on the cardiovasculatory response to exercise in conscious rat. J. Pharmacol. Exp. Ther. 223, 624-630 (1982)

9 Haws, C.W., Gourley, J.K. and Heistad, K.D. Effects of nimodipine on cerebral blood flow. J. Pharmacol. Exp. Ther. 225, 24-28 (1982)

10 Hof, R.P.: Calcium antagonists and the peripheral circulation. Difference and similarities between PY108-068, nicardipine, verapamil and diltiazem. Br. J. Pharmacol. 78, 375-394 (1983)

11 Thyrum, P.T.: Reduced transmembrane calcium flow as a mechanism for the hypoxic depression of cardiac contractility. IRCS Libr. Compend. 1. 1.5 .3 (1973)

12 Vogel, S., Richard, C. and Nick, S.: Blockade of myocardial slow channels by bepridil (ERM1978). J. Pharmacol. Exp. Ther. 210, 378-385 (1979)

13 Kodama, I., Wakabayashi, S., Toyama, J., Shibata, S. and Yamada, K.: Electrophysiological effects of KT-362, a new antiarrhythmic agent with vasodilating action, on isolated guinea pig ventricular muscle. J. Cardiovasc. Pharmacol. 11, 687-693 (1988)

14 Eisner, D.A., Lederer, W.J. and Sheu, S.S.: The role of intracellular sodium activity in the antiarrhythmic action of local anesthetics in sheep Purkinje fibers. J. Physiol. (Lond.) 340, 239-257
(1983)

15 Sheu, S.S., Sharma, V.K, and Vglesity, A.: Sodium-calcium exchange contributes to increase of cytosolic calcium concentration during depolarization in heart muscle. Am. J. Physiol. 250, 651-656 (1986)

16 Hirata, M., Suematsu, E., Hashimoto, T., Hamiachi, T. and Koga, T.: Release of calcium from a non-mitochondrial store site in peritoneal macrophages treated with saponin by inositol 1,4,5-trisphosphate. Biochem. J. 223, 229-236 (1984)

17 Vergara, J., Tsien, R.Y. and Delay, M.: Inositol 1,4,5-trisphosphate, a possible chemical link in excitation-contraction coupling in muscle. Proc. Natl. Acad. Sci. U.S.A. 82, 6352-6356 (1985)

18 Farber, N.E. and Gross, G.J.: Collateral blood flow following acute coronary artery occlusion: Comparison of a new intracellular calcium antagonist (KT-362) and diltiazem. J. Cardiovasc. Pharmacol. 14, 66-72 (1989)

19 Takenaka, T., Usuda, S., Nomura, T., Maeno, $H$. and Sado, T.: Vasodilator profile of a new 1.4dihydropyridine derivate, 2,6-dimethyl-4-(3nitrophenyl) - 1,4-dihydropyridine - 3,5 - dicarboxylic acid 3-(2-(N-benzyl- $\mathrm{N}$-methylamino $))$-ethyl ester 5-methyl ester hydrochloride (YC-93) Arzneimittelforschung 26, 2172-2178 (1976)

20 Sato, M., Nagano, T., Yamaguchi, I., Nakajima, H. and Kiyomoto, A.: Pharmacological studies on a new 1,5-benzothiazepine derivative (CRD-401). Arzneimittelforschung 21, 1338-1343 (1971)

21 Van Breeman, C. and Siegel, B.: The mechanism of alpha-adrenergic activation of the dog coronary artery. Circ. Res. 46, 426-429 (1980)

22 Trump, B.F., Berezesky, I.K. and Cowley, R.A.: The cellular and subcellular characteristics of acute and chronic injury with emphasis on the role of calcium. In Pathophysiology in Shock, Anoxia and Ischemia. Edited by Cowley, R. and Trump, B., p. 6. Williams and Wilkins. Baltimore (1982)

23 Nayler, W.G.: Calcium and cell death. Eur. Heart J. 4. C33 (1983)

24 Wakabayashi, S., Mochizuki, S., Tomiyama, A. and Shibata, S.: Evaluation of cardiovascular effects and antiarrhythmic activity of KT-362 (5- (3- ((2,3,4-dimethoxyphenyl) ethyl) - amino) 1 -oxopropyl) -2.3.4.5 - tetrahydro-1.5-benzothiazepine fumarate), a new intracellular calcium inhibitor (Abstract). Fed. Proc, 45, 803 (1986)

25 Pelc, L.R., Farber, N.E., Warltier, D.C. and Gross, G.J.: Reduction of myocardial ischemia-reperfusion injury by KT-362, a new intracellular caicium antagonist in anesthetized dogs. $J$. 
Cardiovasc. Pharmacol. 13, 586-593 (1989)

26 Golovina, V.A., Zakhrov, S.I. and Bogdanov, K. Yu.: Analysis of antiarrhythmia effects of ryanodine in guinea-pig. J. Mol. Cell. Cardiol. 20, 303-311 (1988)

27 Lynch, J.J., Rahwan, R.G. and Lucchesi, B.R. Antifibrillatory actions of bepridil and buthyl$\mathrm{MDI}$, two intracellular calcium antagonists. Eur. J. Pharmacol. 111, 9-15 (1985)
28 Kahn, M.D., Wittincham, D.J. and Wiesner, K.: Effects of ryanodine in normal dogs and in those with digitalis induced arrhythmias. Am. J. Cardiol. 14, 658-668 (1964)

29 Takasu, M., Suzuki, Y., Shibuya, M., Asano, T., Kanamori, M., Okada, T., Kageyama, N. and Hidaka, H.: The effect of HA compound calcium antagonists on delayed cerebral vasospasm in dogs. J. Neurosurg. 65, 80-85 (1986) 